\title{
As Luzes de Leonor, de Maria Teresa Horta: entre a Literatura, a História e a Filosofia
}

\author{
Maria Luísa Malato \\ Universidade do Porto- ILC 1
}

Resumo: 0 romance As Luzes de Leonor, de Maria Teresa Horta, publicado em 2011, parece-nos incentivar uma livre reflexão sobre a Interdisciplinaridade nos estudos humanísticos, contrariando os que teimam em separar as leituras sobre a História, a Literatura e a Filosofia. Sendo um romance que recusa a classificação de biografia, ainda que baseado nos poemas e nos documentos históricos de/sobre a escritora portuguesa Leonor de Almeida (1750-1839), ele leva-nos a compreender melhor três eixos dos estudos hermenêuticos: a (in)definição da palavra "texto" (do sentido etimológico ao sentido semiótico); a proximidade do discurso histórico e do discurso ficcionado; e o caráter "mais filosófico" da Poesia/ Literatura (Aristóteles), quando comparado com os objetivos da investigação histórica.

Palavras-chave: Interdisciplinaridade/ Post-disciplinaridade, Literatura, Filosofia, História, Hermenêutica, Maria Teresa Horta

Abstract: Leonor's Enlightenment (As Luzes de Leonor), a novel published in 2011 by Maria Teresa Horta, encourages an open discussion about the advantages of the Interdisciplinary Studies in the Humanities, against those who keep defending a very precise gap between History, Philosophy and Literary Theories. The author refuses the classification of "biography" to her novel, based however on a vast amount of manuscripts, written by or about a Portuguese poet, Leonor de Almeida (1750-1839). The literary text - melting truth and fiction - helps us to understand the undeniable link between three axes of the Hermeneutics Studies: the 
(in)definition of the word "text" (its etymological or its semiotic sense); the proximity between historical and literary speeches; and the "more philosophical" idiosyncrasy of Poetry/ Literature (Aristotle), in comparison with the aims of historical research.

Keywords: Interdisciplinary/ Postdisciplinary Studies, Literature, Philosophy, History, Hermeneutics, Maria Teresa Horta

Se devemos buscar a fala da linguagem no que se diz, faríamos bem em encontrar um dito que se diz genuinamente, e não um dito qualquer, escolhido de qualquer modo. Dizer genuinamente é dizer de tal maneira que a plenitude do dizer, própria ao dito, é por sua vez inaugural. 0 que se diz genuinamente é o poema.

(Heidegger, A Caminho da Linguagem)

Porque leremos e releremos As Luzes de Leonor, de Maria Teresa Horta? Porque, escrito entre as malhas da História, da Literatura e da Filosofia, uma vez não basta. Do ponto de vista dos géneros, das estruturas, das vozes narrativas, da funcionalidade, sempre nos parece uma teia de perigosa aranha com a qual jogamos, entre a reverência e o temor da interdisciplinaridade, alternando os percursos (da bibliografia, periodologia, terminologia) a que as disciplinas da História, da Filosofia e da Literatura compelem, rompendo inclusive com as fronteiras da Narrativa, da Lírica e do Drama. Querendo Maria Teresa Horta escrever um romance sobre a vida de Leonor de Almeida, poetisa portuguesa do século XVIII (1750-1839), baseou-o em longos anos de consulta "académica" decifração de manuscritos inéditos, em bibliotecas públicas e privadas, leitura cuidada da bibliografia produzida nas universidades sobre o tempo, a vida e a obra da poetisa. E todavia a própria autora julga dever um esclarecimento ao leitores para que eles não pensem estar perante uma "biografia". Com efeito, esta obra ímpar parece-nos mais uma extraordinária lição de Hermenêutica, que nos demonstra a necessária relação entre os estudos de Literatura, História e Filosofia. 


\section{A (in)definição do "Texto"}

Talvez a essa leitura do romance não seja estranho o Prólogo do romance. Desde essas primeiras páginas, parecem estar associadas o texto e o tecido. Maria Teresa Horta descreve a intriga da vida de Leonor de Almeida, apresentando-a como um bordado, em que é confundível o ato da escrita e o gesto de tecer uma trama. Linha por cima, linha por baixo, a agulha desenharia o direito, o óbvio, e o seu avesso, dissimulado.

Ponto de cruz. Como se a autora deixasse somente traços opostos no direito e traços coincidentes no avesso: "Este é o ritmo dei própria que ela inventa:/ Um poema./ Depois outro poema./ De novo um poema iludindo a paixão./ Parto depois de cada parto./ E de poema" (Horta 2011a: 15).

Ponto cheio. Feito de sobreposições, hipérboles, inverosimilhanças: “O delírio é uma arte que cultiva à pena" (Ibidem).

Ponto de Assis. Em contraste, o desenho feito pelas lacunas da linha sobreposta. Linha por cima, linha por baixo. A agulha delimita o desenho e o desenho da tela que não chega a preencher: "Viagens de poeira e secura à beira das estrelas quase sempre desertas, em incontáveis dias e meses de lentidões absurdas. [...] vai e torna sempre, avesso e regresso na urgência do saber. Por isso de novo sai, se distancia, regressa e fica, por vezes" (Ibidem).

Velhas histórias e metáforas de aranhas nos levam a associar os aracnídeos à escrita feminina, nomeadamente na poesia romântica (Amaral/ Martelo 2006). A etimologia e o mito confirmam-nas mais remotamente. "Textum" é o particípio de "texere", tecer, entrançar, entrelaçar, urdir uma trama (num sentido figurado) e, por extensão, compor, escrever (cf. Ferreira s.d.: 1139). Os mitos gregos associam as mulheres às Parcas, ao Destino/ Moira, trindade que se associa ao tempo, pois eram três as estações para os povos antigos, primavera, verão e inverno, e três as idades de cada um (infância, maturidade e velhice). Hugues Liborel salienta um curioso facto antropológico: nas sociedades tradicionais parece ser privilégio do sexo feminino fazer fios, e tecer seria um dos trabalhos mais antigos concedidos às mulheres (Liborel 1988: 614). As "chansons de toile" medievais eram também significativamente chamadas "chansons d'histoire", sendo em parte líricas e 
em parte narrativas: cantadas pelas mulheres ao tear, contavam uma breve história de amor, uma aventura, entrelaçada com um refrão, como se o desejo da mudança se entrelaçasse com a repetição. A mulher que fia desafia, troca as voltas. Afastadas da palavra pública e publicável, consideradas "por natureza" hiperestésicas, intuitivas, desregradas, desenvolvem a linguagem das feiticeiras, a arte dos enigmas (cf. Gallier 1913). E até por isso nos aparecem ligadas a histórias/ histerias de provocação, em que existe um desejo de conhecer os limites de um poder instituído, a proibição. Aracné é castigada por Minerva, por ter ousado desafiar os deuses com a criação de uma tela: imitou demasiado bem os deuses. A Gata Borralheira pica-se numa roca que estava guardada numa sala em que não podia entrar. Não se sabe até que ponto seria da autoria da Rainha Matilde a longa tapeçaria sobre a batalha de Hastings (1066). Mas é certo que Cristina de Pisão lamentou a vida que a esperava entre teares e contrariando a vontade da mãe, desatou a escrever... À imagem destas cantoras das "chansons de toile" e da mitologia popular, a mulher setecentista tem ainda uma ligação profunda com a literatura oral e evanescente: Catarina de Lencastre, Viscondessa de Balsemão, contemporânea de Leonor de Almeida, ainda que saiba escrever, raramente regista os seus poemas: deixa de possuir secretário certo a partir de 1791 (Maria Ernestina de Almeida apud Borralho 2008: 161), dita sempre os versos com as mãos ocupadas e as poesias são por vezes apanhadas pela filha, pelos amigos, pelos frequentadores da casa, por admiradores mais ou menos anónimos, pelo confessor à hora da morte.

É talvez oportuno recordar aqui um episódio verídico da vida da escritora Leonor de Almeida. Encarcerada ainda criança no Convento de Chelas, com o pai preso no Limoeiro, Leonor abandona a tela que tem na mão e escreve uma carta a seu pai. Conta ela então ao pai que, ao bordar os canhões da casaca do Conde dos Arcos, maravilhada que tinha ficado com a perfeição do seu bordado, imagina que se poderia um dia mascarar de vendedora. Chegando-se por acaso a avistar com o Rei, este, também impressionado com a perfeição do bordado, lhe daria a satisfação de um desejo. A pequena Leonor pediria então a libertação do pai e imagina que o Rei lha concederia, pagando a dívida à tecedeira: "Lembrou-me 
bordá-la de pérolas e, com a perfeição de que são capazes as minhas mãos, fazer com que a aceitasse o apetite de El-Rei (que gosta muito destas bagatelas)" (Alorna 1941: 40-41).

Interessante é ler esta carta em confronto com o mito de Aracné. 0 paralelismo entre Araché que faz a teia, a pequena Leonor que borda a casaca e Leonor adulta que escreve poemas parece-nos evidente. Aracné seria Leonor que borda e Leonor que tece poesias. E Minerva seria aqui o Rei e também o Leitor, persuadidos pela beleza, comovidos e compassivos. A tela é aqui o bordado, da mesma forma que o bordado é o poema que convenceria o deus a dar aos humanos um bem maior: a liberdade. E ainda assim o bordado, o poema, seria "bagatela", valorizada pelo "apetite" de outrem: isco, estratégia, manha, trama. Não sendo este episódio da vida de Leonor de Almeida incluído em As Luzes de Leonor, de Maria Teresa Horta, ele poderia servir de paradigma a todo o romance. Significativamente, o romance inclui, nas primeiras páginas, um semelhante quadro: quando Leonor recorda as lendas e historietas que em pequena inventava para a irmã mais nova, diante da cascata da casa de Sintra:

“A mana inventou isso tudo, julga que não sei? Eu não sou tola!” (Horta 2011a: 23), ripostaria então a ouvinte, um pouco desconfiada da falsidade daquelas bagatelas mas logo rindo, "divertida e maliciosa, pedindo mais contos" (ibidem), porque pedir mais é sempre a única maneira de não duvidar tanto.

[...] encobri paixões ou iludi-as, simulando submeter-me, fingindo ser o meu avesso. (Horta 2011a: 21)

Treinei-me então a esconder os livros apreendidos, que me chegavam de vários e engenhosos modos, ao mesmo tempo que me empenhava no seu estudo. Sem com isto deixar de fazer golas e punhos de renda para nosso uso, ou bordar a ponto cheio as toalhas e os lençóis que as freiras tinham de entregar no Paço, onde já havia chegado a fama da minha rebeldia [...]. (Horta 2011a: 92)

Tal como Penélope, vou tecendo a minha existência. (Horta 2011a: 639)

Se nos demoramos neste feminino fascínio pelos panos, telas, sedas, cores e texturas, é porque o tecido é para Maria Teresa Horta um símbolo hermenêutico de uma guerrilha. 
Não a guerra masculina, de espada longa na mão, mas a guerra feminina, dissimulada no avesso das palavras. Maria Teresa Horta descreve pormenorizadamente os cadernos de Leonor:

Folhas de papel aparadas e medidas, sobrepostas em resmas delgadas, cosidas depois com longas agulhas enfiadas em linha grossa. No final cola-lhes as capas de cartolina, forradas com as sobras dos vestidos, das saias e das blusas dadas pelas pensionistas e as recolhidas. Restos de tecidos lavrados, esboços de hastes e flores harmonizando tons e desenhos esvaídos, ou de seda lisa verde-lima ou veludo escarlate, atravessados de onde em onde por um ligeiríssimo brilho ruivo ou ondulação de marfim [...]. (Horta 2011a: 60)

A escrita de Leonor em Chelas é um patchwork de cantigas frágeis, dizeres, citações de leituras proibidas, estiletes, penas e silêncios pesados, de elipses e reticências, preterições e profecias, de ironias invisíveis ou de metáforas ingénuas. Como de resto, de alguma forma, os primeiros poemas de Maria Teresa Horta, ainda evitando a imagem óbvia, falando da "sombra circular duma grande curva do silêncio", do "penúltimo sexo das abelhas" ou do preto/ convento redondo em nós, antigamente" (Horta 2009: 45, 38, 74). Estratégia feminina de quem sabe de tecidos. Porque dissimula e tapa. Só o que não é óbvio nos pede interpretação: "Nous parlons d'interprétation lorsque la signification d'un texte ne se comprend pas de prime abord. [...] En effet ce qui est immédiatement évident, ce qui nous convainc par sa simple présence, ne réclame aucune interprétation" (Gadamer 1963 : 10).

Há que considerar, em toda a interpretação, uma troca de valores equivalentes, nunca iguais (inter+pretium), por vezes até a fúria das coisas dissimuladas e reprimidas, as entrelinhas, o fio que vai por trás. Às figuras das mulheres do povo que, durante a Revolução Francesa, tricotavam enquanto assistiam ao desfile das execuções mecânicas da guilhotina, corresponde aquele "fio dobrado da raiva das mulheres", e o esquartejamento do Major Belsunce pelas suas vítimas, referidos no romance de Maria Teresa Horta (Horta 2011a: 644, 654). Do sentimento público ao sentimento dissimulado, das primeiras páginas às últimas, se afirma pois a empatia entre Leonor de Almeida e Maria Teresa Horta, 
misturando-se uma com a outra nas frases próprias e atribuídas. "Não sei o que é em mim memória ou recriação", reproduz Maria Teresa Horta na pena de Leonor de Almeida (Horta 2011a: 21). E escreve no final sobre Leonor: "ao pretender conhecer-te, em tudo te descubro e reinvento" (Horta 2011a: 1054).

$\mathrm{Na}$ verdade, esta identificação é uma forma de rotura com "o confessionalismo imediato e a emotividade efusiva" que a autora recusa "peremptoriamente" (Maria João Reynaud em Horta 2011b: 23-24). E por isso deve ser vista como uma aproximação ao estatuto do "intérprete", do "hermeneuta", aquele que deseja compreender o que dele não faz parte, não sendo todavia capaz de deixar de ser quem é e de naturalmente reconhecer os pontos de confluência. Hermes, deus da transmutação e dos caminhos cruzados que daria supostamente o seu nome à própria Hermenêutica, remete para esse Angelus, que pontualmente atravessa o romance de Maria Teresa Horta e vai servindo de "intermediário". É ele o mensageiro que nos aproxima da inteligibilidade das coisas, e por isso vai aparecendo entre os textos da própria Leonor de Almeida e aqueles que Maria Teresa Horta produz a partir deles.

Maria Teresa Horta tem a noção de que a narradora omnisciente que escreve $A s$ Luzes de Leonor não se pode confundir com a escritora Maria Teresa Horta. E por isso, certamente, Maria Teresa Horta editou em separado os poemas que fazia enquanto escrevia o romance, os seus poemas, não as palavras do Angelus (Horta 2011b: passim, max. 944), mas aqueles pelos quais se levantava do computador para escrever em papéis mais reduzidos que o A4: os Poemas para Leonor, só publicados um ano depois, em 2012. A polifonia do romance de Maria Teresa Horta recorda-nos que não é possível tratar a linguagem como um objeto externo à linguagem: toda a linguagem sobre a linguagem entrecruza o sujeito e o objeto, a ponto de termos de reconhecer que só nos movemos linguisticamente numa interseção:

Poderíamos perguntar qual o horizonte interpretativo que um grande texto literário habita e, depois, como é que o horizonte do próprio mundo de intenções, esperanças e pré-interpretações de um indivíduo se relaciona com ele. Esta fusão de dois horizontes deve ser considerada um elemento básico de toda a interpretação explicativa." (Palmer 1986: 35) 
Quando começaria esta identificação entre autora e personagem? Se relermos o primeiro livro de poemas de Maria Teresa Horta, Espelho inicial, notamos já a presença do espaço conventual nos seus campos semânticos que a aproxima já daquele Convento de Chelas em que está encarcerada a filha de D. João de Almeida, genro dos velhos Távoras: "monge”, "monjas", "freira”, "igrejas”, “anjos", "vigília”, “deserto”, que mais tarde se vão manter na ambiguidade das palavras "cela" ou "chagas", do "destino do minuto/ na grade", do potencial subversivo/ sexual de um "quarto obscuro" ou de "pupilas triangulares/ e breves/ dum convento" (Horta 2009: 36, 40, 50, 53, 85, 91, 152 et passim). Desde os primeiros livros de Maria Teresa Horta se nota um fascínio tópico pelos lugares e objetos que conotativamente nos remetem para um espaço claustrofóbico que encerra mulheres e crianças, espaço antigo, arcaico, entre o "simbolismo" revivalista ou o gosto "neoclássico" revisitado. Dele terão um dia que sair. Repare-se na "arcada”, na "clepsidra”, no "punhal”, na "missiva”, no "castiçal”, no "candelabro", na "pérgula”, na "harpa”, nos colos "de garça”, na "medusa", nas "ondinas" ou na evocação, que paradoxalmente parece mais sonora que visual, do "cardo", da "granada", do "saxe" ou do "marfim", quiçá a ainda mais remota do "castelo", da "princesa" e dos "cavaleiros", e dos "palácios dentro/ de soluços/ conventos de freiras a pensar" (Horta 2009: 29, 30, 32, 35, 36, 37, 40 et passim).

\section{A História e as histórias}

Podíamos largamente dissertar sobre as diferenças entre a Literatura e a História, cabendo à primeira largar o freio da invenção verosímil e à segunda tomar o freio da verdade. A própria autora nos ajudaria na tarefa, ao afirmar que não quis fazer uma biografia histórica: evitou até a designação de "romance histórico", com que agora se cativa um público convencido de que pode aprender História lendo romances. Na capa, identificase o género: "romance", somente. Mas o que mais nos surpreende quando lemos este "romance" é a quantidade de documentos históricos que reconhecemos, de livros impressos sobre a época (apresenta-se uma Bibliografia, nas últimas páginas). Reconhecemos sobretudo papéis pouco acessíveis que vimos por vezes na Torre do Tombo, na Biblioteca 
Nacional ou no Arquivo Geral do Exército. 0 tamanho do romance (cerca de mil páginas que decorrem de mais de 14 anos de pesquisa) e a estrutura polifónica dos fragmentos de discurso são o corpo mais óbvio do valor da informação, cujo rigor não hierarquiza fontes e autoridades. Se Maria Teresa Horta transcreve cartas ou se cria ou recria os seus testemunhos, se enuncia uma linguagem poética e acrónica, é invariavelmente reproduzindo testemunhos semelhantes, quase sempre guardando os factos e as datas dos documentos...

Não sendo um "romance histórico", pelo menos no sentido que o género vai ultimamente tomando, As Luzes de Leonor é uma notável reflexão sobre a história. Não tanto a História enquanto disciplina científica, embora também se lhe possam aplicar algumas observações mais específicas sobre o século XVIII, mas sobretudo a história enquanto "distância temporal", no sentido que lhe dá Gadamer:

Car contrairement à ce qu'on a souvent imaginé, le temps n'est pas un précipice qu'on devrait franchir pour retrouver le passé ; il est en réalité le sol qui porte le devenir, et où le présent prend ses racines. [...] Elle n'est pas une distance à franchir, mais une continuité vivante d'éléments qui s'accumulent pour devenir une tradition qui, elle, est la lumière où tout ce que nous apportons avec nous de notre passé, tout ce qui nous est transmis fait son apparition. (Gadamer 1963: 81-2)

É difícil, neste romance sobre Leonor de Almeida, separar o que é do domínio da História e o que é do domínio da ficção. Paul Veyne chamou já a atenção para a similitude das estratégias de verosimilhança, isto é, do que é confundível com a verdade. A História não é o fruto de um determinismo atómico: é feita de escolhas de intriga, e de personagens, composta afinal pela "mesma matéria que a vida de cada um de nós":

Notre propre existence, après tout, ne nous apparaît pas comme une grisaille d'incidents atomiques ; elle a d'emblée un sens, nous la comprenons; pourquoi la situation de l'historien serait-elle plus kafkéenne? L'histoire est faite de la même substance que la vie de chacun de nous. (Veyne 1971: 50)

Leonor de Almeida é, desde logo, explicitamente, uma antepassada de Maria Teresa Horta, uma personagem histórica que se confunde com as leituras e imagens dos sítios 
comuns onde Maria Teresa Horta passou a infância e a adolescência. Também as ousadias de Leonor de Almeida se confundem com as ousadias de Maria Teresa Horta, já na idade adulta. Irrompem ambas em espaços tradicionalmente masculinos. Usam ambas a literatura para reivindicar o direito à palavra.

Em 10 de maio de 1773, ainda encarcerada no Convento de Chelas, Leonor de Almeida escreve a uma sua amiga, a jovem Teresa de Mello Breyner, sobre os escândalos que causavam algumas das suas leituras ou comportamentos: "Eu desejo que todos sejam como devem ser; não quisera que a minha conduta desse que sentir a ninguém; tais são os meus desejos; se é diferente a minha fortuna, paciência" (cf. Anastácio 2007: 55).

A 2 de maio de 1973, o Diário de Lisboa anunciava que as escritoras e o editor das Novas Cartas Portuguesas tinham sido acusados de "abuso de liberdade de Imprensa" pela publicação do livro, entretanto retirado das livrarias "em consequência dos problemas de ordem moral que levanta" (Diário de Lisboa 1973: 24).

Poucas autoras há como Leonor de Almeida, em Portugal e na Europa do século XVIII, assim rebeldes. Poucas autoras também há como Maria Teresa Horta, cuja obra literária sempre foi considerada excessiva e ameaçadora, até para as mais primaveris ditaduras. Talvez a empatia com Leonor de Almeida se tenha de ler neste cruzamento histórico das histórias individuais.

Neste romance, cuja elaboração se prolongou por mais de catorze anos, lá está Virginia Woolf como epígrafe, a relembrar a sua relação umbilical: "Vivi em ti todo este tempo - agora, que eu parto, com quem te pareces tu, verdadeiramente?" (Horta 2011a: 13). Não sabemos, talvez não saibamos nunca, até que ponto existe uma identificação entre a protagonista do romance e a autora, ligadas pelos laços do sangue: o que mais buscamos é o que mais nos escapa... "O excesso como arma ou como pena, na verbena das tardes, quando nela tudo volteia, se incendeia e arde", continua a aranha do Prólogo, avisando os insetos incautos. "Poética nascida de uma exigência radical de liberdade", confirma Maria João Reynaud no prefácio à Poesia Reunida, de Maria Teresa Horta, autora de muitas variantes do "Poema da insubordinação" (Horta 2011b: 22 e 67).

Consequentemente, as luzes de Leonor não são tanto as Luzes do século XVIII, 
circunscritas pelas datas da vida de Leonor (1750-1839), aqui tratadas de 1754 a 1803.0 Iluminismo de que aqui se fala não é fielmente o dos manuais de História da Literatura. Mas exemplifica muito claramente o sentido que Kant dava às "Luzes": "Sapere aude. Ousa saber". Lê, pensa, escreve. Ainda que essa ousadia signifique afrontar o conveniente, o decoroso, ou o verosímil (que não é por vezes senão aquilo que alguns dizem que é a verdade). Tarefa ainda mais heroica se considerarmos que estamos a falar da Mulher, do "belo sexo", de seres feitos "pela Natureza" para fazer filhos, dar repouso ao guerreiro, responder ao desejo, mas seres histéricos, emotivos, que calam palavras, razões e desejos. E “é tão cómodo ser inferior", constatava Kant, ao proclamar as Luzes no feminino...

Il est si commode d'être mineur... Si j'ai un livre qui a de l'entendement pour moi, un directeur spirituel qui a de la conscience pour moi, un médecin qui pour moi décide de mon régime, etc, je n'ai pas besoin de faire des efforts moi-même. [...] Que de loin la plus grande partie de l'humanité (et notamment le beau sexe tout entier) considère le pas à franchir pour accéder à la majorité comme non seulement pénible, mais encore dangereux, c'est à quoi s'appliquent ces tuteurs qui ont eu l'extrême bonté de se charger de sa haute direction. (Kant 1991: 73)

Nesse sentido, o romance de Maria Teresa Horta inscreve-se numa contemporaneidade abalada, no século XXI (à semelhança do que ocorrera no século XVIII), pelos fenómenos de inter-relação multinível a que alguns filósofos chamam "Postdisciplinaridade" (cf. Moyano/ Coelho/ Mayos 2014). São épocas que desenvolvem "filosofias da suspeita" em que a possibilidade de saber se realiza pela possibilidade de cruzar perspetivas. Richard Palmer tinha razão quando afirmava que toda "a experiência hermenêutica é "intrinsecamente histórica" (Palmer 1986: 243), porque exige uma contraposição das memórias. 0 progresso da consciência histórica estabelece-se numa tensão dialética, entre a memória da tradição e a nossa memória, entre os preconceitos que nos cegam e os que nos iluminam, nesse propósito de "distinguer les préjugés qui aveuglent de ceux qui éclairent" (Gadamer 1963: 82). Talvez por isso (pelo menos para os "ratos de biblioteca" que conhecem o século XVIII pelos seus documentos de arquivo) é também o excesso ficcionado deste romance que leva à aceitação do inverosímil e do indecoroso no 
século XVIII, suspeitando-o ainda no século XXI. Dessa (in)verosimilhança da História se encontrariam muitos "documentos" nesta obra de Literatura. E os pormenores que Maria Teresa Horta coloca no texto (que tirou dos muitos manuscritos da época que leu e assinala com aspas e itálico) bem nos podiam alertar para o muito que há ainda a fazer no domínio da História Privada, pelo menos na historiografia nacional, sendo certo que se não pode adotar o ritmo da cronologia francesa (Monteiro 2011: 7).

Histórias de crianças que morrem enfaixadas, abafadas em cortinas de tule e veludo. De jovens mulheres que escrevem e disfarçam os poemas em cadernos forrados com restos de vestidos. São incompreensíveis os silêncios da História sobre as crianças, as noviças, as mulheres, todas guardadas para dentro de portas. Está tudo lá um pouco, em As Luzes de Leonor, recordando-nos que poucos estudos há ainda sobre a nossa história da sexualidade, a violência do coito por obrigação, as superstições ligadas à masturbação, menstruação, conceção, gravidez, os mitos do parto ou do puerpério, as diferentes opiniões médicas sobre o aleitamento, as técnicas cirúrgicas ou químicas para provocar o aborto, os movimentos das "fazedoras de anjos". Esquecemo-nos que as mulheres e os homens as podiam ler também em Ovídio, nas elegias XIII e XIV dirigidas a Corina, ou nas divagações marítimas de Aulo Gélio, entre as páginas consagradas de Os Amores ou das Noites Áticas (cf. Aguiar 1951: passim). Maria Teresa Horta recorda ainda uma carta de Leonor em que esta narrava o momento em que descobriu que as ligaduras que enfaixavam a Infanta recém-nascida lhe tinham partido alguns ossos (Horta 2011a: 544).

Histórias de mulheres que buscam alternativas aos dois únicos espaços que lhes eram consentidos: a casa ou o convento/asilo. Mulheres que cortam o cabelo e se libertam da cabeleira e do espartilho. Como ler de outra forma as ousadias de não apanhar o cabelo, de usar as "cores claras da luxúria", de usar um casaco "à caçadora", de ocultar a testa e os olhos, fazendo risco, cortando "marrafa", usos que tanto escandalizavam José Daniel Rodrigues da Costa e o público dos folhetos de cordel? 0 tamanho e forma do cabelo, o tamanho e a cor da roupa são efetivamente formas de afirmação das mulheres no mundo masculino. Ainda que não tão transgressoras quanto os textos de Olympe de Gouges ou os comícios de amazonas de Théroigne de Méricourt, devem ser lidas como uma linguagem de 
provocação, como nos recorda Maria Teresa Horta, quando parece falar somente de brigas sobre toucas e trapos.

Histórias de mulheres que escandalosamente desejam, não conseguindo ser somente o objeto do desejo, ainda quando envelhecem e a idade infértil lhes torna o desejo ainda mais inconveniente. Como ler de outra maneira os versos da Viscondessa de Balsemão, companheira de armas da Marquesa de Alorna?

Posto que entre os meus cabelos/Comece a neve a cair,/ Inda sinto aquele fogo/ Com que o posso desmentir./ [...] Quando passaram três dias/ Sem que... nem quero dizê-lo,/ Tu me desses vivas provas/ De um carinhoso desvelo? (Borralho 1999: II, R374-6)

O tema destas mulheres viris, sexualmente possuidoras de uma voz ativa, encontrase em muitas personagens literárias, com muitas variantes simbólicas (nas Amazonas, nas Valquírias, em Artemis, nas Fúrias e nas Bacantes, em Medeia, nas donzelas que se disfarçam de soldado, formas singulares ou coletivas de uma força que se tem como poderosa mas dissimulada. Muitos romances do século XVIII tornaram protagonista a mulher que se disfarça de homem. No romance As Luzes de Leonor se ouve um eco de tudo isto quando imagina Leonor que exclama a sua "pressa assanhada": "Desejo demasiado exaltado, dizem, para uma mulher. Sobretudo se para uma mulher da minha idade" (Horta 2011a: 359). De Teresa de Mello Breyner existem algumas cartas a Leonor, falando-lhe de como era importante não parecer mulher de letras ("pelo silêncio a que condenei as minhas trovas, consegui não perder o conceito de pessoas serias") e dos boatos de que teria sido o P.e Francisco José Freire a escrever a sua Osmia, publicada anónima: “dá uma risada quando ouvires [...]". (apud Bello Vazquez, 2004: 171-2).

Histórias caladas, mais do que histórias privadas. Este anonimato, esta revolta surda, este excesso inverosímil, Manuel de Figueiredo retratou-os, colocando duas mulheres na Lua, a reivindicar uma honra para todos o mais absurda, a viver uma epopeia que para todos os mais era uma farsa: é esse o enredo da sua peça Grifaria. Sob outra forma, Maria Teresa Horta retrata igualmente esta mesma epopeia, ao ir salientando em Leonor o gosto por Homero e Vergílio, pelos romances de cavalaria, o "heroísmo" das mulheres que teimam 
em pensar, ler, estudar, ter pensamento próprio, a busca do herói que lhe falta, a tentação que lhe vem de escrever um longo poema a partir da Ilíada, e a consciência de ser Penélope que resiste sem Ulisses (Horta 2011a: max. 682, 729). A realidade é quase sempre muito mais improvável do que a História, exageradamente moldada pelo verosímil. Depois de ler o romance de Maria Teresa Horta, torna-se evidente, porém, que há, na História da Literatura, alguns silêncios convenientes, decorosos, inverosímeis.

Não sendo sobre Interdisciplinaridade, os estudos de Carlo Ginzburg e Giovanni Levi revestem-se de uma grande importância. Falam de uma Micro-história, em que os agentes da História são, mais do que os protagonistas políticos, os figurantes de fundo: os indivíduos singulares, as exceções, os marginalizados, por vezes até os anónimos. Trata-se de uma escala reduzida de focalização que, no dizer dos dois historiadores, não deve ser confundida com a história das mentalidades, mas antes como um zoom na fotografia. Não dispensa o enquadramento temático, mas segue o filamento quase invisível que une o particular ao universal, mapeando os nexos quase invisíveis de causalidade entre os factos "notáveis" e os factos "ignoráveis", com um extremo cuidado das fontes:

Pode comparar-se esta pesquisa ao acto de seguir os fios de um trabalho de tecelagem. Chegamos a um ponto em que podemos ver que estes fios formam um todo coerente, um tecido homogéneo e estreitamente urdido. Para verificarmos a coerência do padrão, percorremos com o olhar diferentes linhas. (Ginzburg 2016: 58)

\section{Literatura e Filosofia}

O conceito de verosimilhança, ao contrário do que sucede com o conceito de verdade, baseia-se invariavelmente na prática dos critérios da "intuição". Carlo Ginzburg, no subtilíssimo ensaio Morelli, Freud e Sherlock Holmes, lança algumas pistas sobre a emergência de um "modelo epistemológico" que "veio a tornar-se operativo sem se ter construído enquanto teoria explícita", mas que "talvez possa ajudar-nos a ir para além da estéril oposição entre 'racionalismo' e 'irracionalismo'”. Tal modelo epistemológico radicaria num "paradigma conjectural da semiótica" em que a prática sistemática da observação visa o reconhecimento do excecional, a racionalidade do intuitivo (Ginzburg 
2016: 13 e 60-72). É certo que a intuição é vista, ainda hoje e em geral, como um elemento de subjetividade que, não se podendo confessar nas humanidades, se passou a ocultar em nome da desejada objectividade das "ciências humanas" ou das "ciências sociais". Faz parte de uma arrastada guerra entre as ciências e as letras em que os que se sentem vencidos copiam os vencedores (Bonald apud Compagnon 2010: 25). 0 próprio Ginzburg duvida que o paradigma conjetural possa atingir um rigor compatível com a expectativa criada pelas ciências naturais, de direção quantitativa e anti-antropocêntrica. Mas não deixa de sublinhar que a "intuição" a que esse paradigma se refere nada tem de extra-sensorial, ainda que essa possa ser uma das suas máscaras: é essencialmente uma "capacidade de saltar do conhecido para o desconhecido por meio de inferências (com base em indícios)" (Ginzburg 2016: 71-2).

Mutatis mutandis, o romance de Maria Teresa Horta parece responder a este mesmo fascínio de Ginzburg pelo modelo epistemológico da intuição. Oriundo de contextos difusos, os indícios que a autora vai espalhando pela obra - dos tipos "venatório, divinatório, conjectural ou semiótico" (Idem: 59) - vão exercitando no leitor uma sensibilidade intuitiva, efeito de uma retórica dos sentidos (Malato 2014-16: 188-197).

Não é propriamente um plano.

Terá mais a ver com uma descoberta, uma ideia que começa a germinar no meu pensamento; um projecto a ser arquitectado com vagares de gosto, a tomar corpo, tendo como única finalidade a mudança de rumo da minha vida. [...] A demanda da minha própria vida. (Horta 2011a: 180)

Algumas frases aparecem repetidas, como se fossem metáforas obsessivas que marcam o estilo da autora ou da personagem: "Toca Mozart de manhã cedo", "Ultimamente tem sentido desejo de comer flores”, “Terás de partir fugido, meu amor”, "Elas tecem”...

Richard E. Palmer recorda oportunamente uma indicação de Aristóteles que situa o momento da interpretação numa fase anterior ao da análise lógica, não as fazendo coincidir como parece suceder no "pensamento moderno" (Palmer 1986: 32). E talvez se deva ler num texto de Heidegger as razões para esta observação de Palmer, quando nos remete para a importância do "pathos", elemento radical da empatia, no processo hermenêutico. Não o 
"pathos" que normalmente se traduz por "paixão" ou "emoção passiva", mas aquela que, no dizer de Heidegger, se devia antes traduzir por "espanto" ou "assombro", sentimento que Platão identifica até como sustentáculo de toda a filosofia:

Platón dice (Teeteto, 155d) [...] 'Verdaderamente es por completo de un filósofo este "pathos" - el asombro’; pues no hay ningún outro desde-dónde que domine la filosofia, fuera de éste'. [...] El "pathos" del assombro no está simplesmente al comienzo de la filosofia al modo cómo, por ej., el lavado de las manos precede la operación del cirujano. El assombro sostiene y domina [cf. "arché"] por completo la filosofia. (Heidegger 1960: 50)

Talvez possamos até utilizar algumas das teses de Richard Palmer para ir demarcando alguns dos caminhos propostos para a interpretação por Heidegger e Gadamer, que nos parecem especialmente pertinentes para a lição de hermenêutica que lemos em As Luzes de Leonor. Desde logo a afirmação de que "a experiência hermenêutica é ontológica” e "intrinsecamente linguística” (Palmer 1986: 243). Não porque a compreensão e a linguagem revelem "o ser das coisas" como se ele fosse "um objeto face a uma subjectividade", mas porque a compreensão e a linguagem "iluminam o ser em que nos situamos" (ibidem). Não será por acaso que Maria Teresa Horta, ao escolher como epígrafe do Espelho Inicial uma frase sartriana de Simone de Beauvoir, ("toute ma présence est parole"), é sensível, em As Luzes de Leonor, a esta conformação da linguagem à linguagem. É esse círculo "viciado" que leva Leonor a chamar às freiras "esdrúxulas", a provocar os algozes pronunciando o nome proibido dos Távoras, a ocultar todavia o nome de Voltaire, a evitar o "não" como o "sim", e depois ainda a pedir licença para ler livros proibidos, licença para frequentar as bibliotecas: "É necessário descobrir, encontrar o cerne, o núcleo da harmonia. Da sua metáfora. Para a nomear ou para a iludir?” (Horta 2011a: 65, 59, 67, 83).

Para Leonor como para Maria Teresa Horta, a presença que a palavra dá a quem as escreve não pode, no entanto, ler-se fora de uma presença que os que escrevem dão à palavra: as palavras nunca são o que são. Têm um tempo, um ritmo, uma melodia e, acima de tudo, um tempo/espaço retórico oportuno ("kairós") que lhes aumenta a eficácia ou lhes torna romba a agudeza. Por isso é interessante considerar no romance de Maria Teresa 
Horta não somente a polifonia das vozes permitidas ou interditas, já referida, mas a visão caleidoscópica do tempo e do espaço, visados ou desejados. Com efeito, aquele que é o tempo (ou o espaço) de Leonor é sempre um tempo (ou um espaço) presente cruzado pela recordação dos passados e pela imaginação dos futuros, pela recriação proporcionada pelas leituras ou pela escrita. É o tempo da Marquesa Velha, sua avó, perigosa como ela. 0 tempo dos presságios, de que as mulheres da família têm o condão. 0 tempo das personagens que a cercam, a mãe, a irmã, o marido, os amantes, os criados. 0 tempo dos livros lidos, diferente do tempo dos livros relidos. O tempo de Homero, Ovídio, Petrónio que se junta ao tempo de Voltaire, de Rousseau, de Diderot, ainda ao tempo de Goethe e de Schiller (Horta 2011a: 355-6). 0 tempo feminino, daquelas insubmissas que deixaram o tear, das que abraçaram a liberdade da clausura, das que pegaram na pena: de Leonor da Aquitânia, de Cristina de Pisão, de Hildegarda de Bingen, de Santa Teresa de Ávila, mas também já de Mme de Stael, de Olympe de Gouges, de Théroigne de Méricourt (Horta 2011a: v.g., 134).

0 tempo de Leonor cruza-se também com o tempo, as leituras e os textos de Maria Teresa Horta, hermeneuta que não pode deixar o presente para conhecer o passado, nem esconde do leitor o facto de não o poder ou querer esquecer. É porque "a experiência hermenêutica compreende o que é dito à luz do presente" (Palmer 1986: 245) que à memória recriada de Leonor se junta naturalmente/ obviamente a memória recriada de Maria Teresa Horta, e as "palavras de poetisas do futuro" que iluminam as palavras escondidas ou não-ditas por Leonor. No texto, percorrido por constantes analepses e prolepses, memórias e profecias, aparecem, entre as mais verosímeis referências setecentistas, a visão premonitória de Lílias Fraser, personagem de Hélia Correia, as Coisas de Partir, de Ana Luísa Amaral, ou as alusões que evocam subliminarmente as Novas Cartas Portuguesas, de Maria Isabel Barreno, Maria Velho da Costa, Maria Teresa Horta (cf. Horta 2011a: v.g., 781, 790).

Parece como si planteássemos sólo preguntas historicizantes (historische). Pero en verdade meditamos sobre la esencia futura de la filosofia. Intentamos escuchar la voz (Stimme) del ser. (Heidegger 1960: 55) 
Compreende-se então facilmente a velhíssima reflexão de Aristóteles sobre o caráter "mais filosófico" da Poesia (Literatura):

Pelas precedentes considerações se manifesta que não é o ofício do poeta narrar o que aconteceu; é, sim, o de representar o que poderia acontecer, quer dizer: o que é possível segundo a verosimilhança e a necessidade. [...] Por isso a poesia é algo de mais filosófico e mais sério do que a história, pois refere aquela principalmente o universal, e esta, o particular. (Aristóteles, 1986: 115, cf. Poética, 1451b)

O que se lê pelo punho de Maria Teresa Horta, refletindo sobre estes variadíssimos elos que vão unindo os vários tempos e os vários espaços, vividos ou imaginados por mulheres "submetidas à vergasta da violência", caladas, internadas como loucas, "para sempre perdidas", faz a universalidade da Literatura como faz a universalidade da Filosofia. A escritora, como o filósofo, não tem de inventar factos novos ou dizer coisas novas, mas tem de dizê-lo de novo, refazendo em cada momento a "verdade" do mito, o que permanece para além da particularidade de um espaço ou um tempo. Escrever/ publicar torna-se uma missão que pretende dar testemunho, voltar à caverna, fazer ver, fazer sentir, fazer pensar. Maria Teresa Horta sabe que só o facto de tornar suas as vidas caladas e os pensamentos não ditos justifica o facto de escrever sobre as luzes. É das luzes que se trata, ainda que se trate das luzes de Leonor, de Sophie de Condorcet, das suas ou das nossas:

Leonor, tal como Sophie de Condorcet, reconhece que a escrita tem o condão de resguardar, de salvar, encaminhando-a para a perenidade necessária à posteridade pretendida. (Horta 2011a: 795)

Das afirmações anteriores decorre pois que "a experiência hermenêutica é intrinsecamente dialéctica", sendo a razão uma "ratio", isto é, a expressão de uma correspondência, e nunca podendo a linguagem sobre a verdade fazer-se a não ser por metáfora, transporte, transfiguração ou transformação da linguagem (Palmer 1986: 243). Resta aos hermeneutas continuar a falar, não como se contrapusessem monólogos, mas tão só para tentar compreender: 
$\mathrm{P}$ - Falar sobre a linguagem quase que inevitavelmente a transforma num objecto.

J - Nesse caso, sua essência, seu vigor desaparece.

P - Nós nos pomos acima da linguagem ao invés de escutar a partir da linguagem.

J - Só então poderia haver uma fala a partir da linguagem...

P - ... a modo de um apelo que, partindo de sua essência, caminhasse em sua direcção.

J - Como conseguir isso?

P - Falar a partir da linguagem só pode ser uma conversa.

J - E sem dúvida estamos conversando. (Heidegger 2003: 116)

A conversação sobre Leonor (de que "o romance polifónico" de Maria Teresa Horta faz prova) é, em grande medida, a imagem alargada desse diálogo sobre a linguagem, o poder e a fragilidade das palavras, ditas ou escritas, manuscritas ou impressas. Poderemos dizer que um "texto literário" não pode demonstrar um argumento da mesma forma que o faz um "texto não-literário". Concedamo-lo ainda, sem que seja necessário anteceder tal debate de um outro, mais problemático, sobre o que distingue um texto literário de outro que o não é. 0 texto literário mostra, mais depressa do que demonstra. Mas permanece válida nele a afirmação da incompletude ou da ambiguidade de toda a "ex-plicação" (abertura das dobras/ plies) da linguagem, ilustrado pelos diálogos de Sócrates sobre a dialética ou por esta conversa de Heidegger que os imita...

J - Mas será então que devemos simplesmente nos esquivar a qualquer esforço e nos abster do risco de falar da linguagem?

P - De forma alguma. Temos de nos esforçar incessantemente para falar da linguagem. Contudo, o que então se conseguir dizer nunca poderá assumir a forma de um trabalho científico... (Ibid: 115-6)

É importante ler As Luzes de Leonor, aceitando o desafio nele implícito, lamentando somente o nosso espírito "não ter sido mais voraz, mais tenaz, mais implacável, sem arrependimento de nada", como imagina Maria Teresa que Leonor possa ter dito. Não o lamentaremos todos nós um dia? Lido assim desde as primeiras páginas (como aliás achamos que este romance deve ser lido), depressa diremos que este romance é sobre a verdade do excesso, a verdade do "pathos", do assombro que provoca o conhecimento. 
Como meio e fim. Sem que se atente às fronteiras que impeçam de ver a unidade desse conhecimento, que se poderá então dizer, "interdisciplinar". É o seu "excesso ameaçador" que nos leva a duvidar da "verosimilhança" de alguma "libertinagem", do "decoro" de algumas formas de manipulação da linguagem, masculina ou feminina, da "veracidade" de alguns episódios de época, as da época que estudamos e a nossa. Distraídos que andamos por vezes a separar em Literatura o particular histórico que leva ao universal filosófico. Habituados que estamos a que haja vozes de fundo que parecem cantar coisas inocentes, tendo sempre as mãos ocupadas.

\section{NOTA}

\footnotetext{
${ }^{1}$ Este artigo foi desenvolvido por Fundos Nacionais através da FCT - Fundação para a Ciência e a Tecnologia, no âmbito do do Programa Estratégico “UID/ELT/00500/2013” e por Fundos FEDER através do Programa Operacional Fatores de Competitividade -COMPETE “POCI-01-0145-FEDER-007339”.
} 


\section{Bibliografia}

Aguiar, Asdrúbal de (1951), Estudos relativos à reprodução na Antiga Roma (Menstruação, Concepção, Gravidez, Parto, Puerpério, Aleitamento, Recém-Nascido, Aborto), Lisboa, s.n., 1951.

Alorna, Marquesa de (1941), Inéditos. Cartas e outros Escritos, selecção, prefácio e notas do Prof. Hernâni Cidade, Lisboa, Sá da Costa.

Amaral, Ana Luísa/ Martelo, Rosa M. (2006), "Aranhas e Musas: representações de poeta, subjectividades e identidades na poesia", Cadernos de Literatura Comparada 14/15, [Porto], p. 31 ss.

Anastácio, Vanda, org. (2007), Cartas de Lília e Tirse (1771-1777), Lisboa, Colibri/ Fundação Casas de Fronteira e Alorna.

Aristóteles (1986), Poética, ed. Eudoro de Sousa, Lisboa, Imprensa Nacional-Casa da Moeda. Bello vázquez, Raquel (2004), "Dá uma risada quando ouvires...". Transgressão e ocultamento em Teresa de Mello Breyner, in "Mulheres Más. Percepção e Representações da Mulher Transgressora no Mundo Luso-Hispânico", Vol. I, Porto, Univ. Fernando Pessoa, pp. 159-175.

Borralho, Maria Luísa Malato (2008), "Por acazo hum viajante...". A vida e obra de Catarina de Lencastre, 1. ․ Viscondessa de Balsemão (1749-1824), Lisboa, IN-CM.

Compagnon, Antoine (2010), Para que serve a Literatura?, trad. José D. de Almeida, Porto, Deriva/ ILCML.

Escritores no banco dos réus (1973), Diário de Lisboa, 2 de maio, p. 24. $<$ http://www.fmsoares.pt/aeb online/visualizador.php?bd=IMPRENSA\&nome da pasta=0 6817.167.26348\&numero da pagina $=24>$ (acesso em 20/5/2017).

Ferreira, A. Gomes (s.d.), Dicionário de Latim-Português, Porto, Porto Editora.

Gadamer, H.-G. (1963), Le Problème de la Conscience Historique, Louvain/ Paris, Publ. Univ. 
Louvain/ Ed. Bétrice-Nauwelaerts.

Galeffi, Romano (1966), A Autonomia da Arte na Estética de B. Croce, Coimbra, Atlântida.

Gallier, Humbert de (1913), Filles Nobles et Magiciennes, Paris, Calmann-Lévy.

Ginzburg, Carlo (2016), Morelli, Freud e Sherlock Holmes. Indícios e Método Científico, Porto, Deriva/ ILCML.

Heidegger, M. (1960a), Chemins qui Mènent Nulle Part, trad. W. Brokmeier, Paris, Gallimard.

--- (1960b), La Pergunta por la Cosa, trad. E. Belzunge, Z. Szankay, Buenos Aires, Sur.

--- (1960c), Qué es eso de Filosofia?, trad. Adolfo Carpio, Buenos Aires, Sur.

---- (2003), A Caminho da Linguagem, trad. Márcia Schuback, São Paulo, Vozes, max. texto “De uma conversa sobre a linguagem entre um japonês e um pensador”, pp. 71-120.

Horta, Maria Teresa (2011a), As Luzes de Leonor, A marquesa de Alorna, uma sedutora de anjos, poetas e heróis, Lisboa, D. Quixote.

---- (2011b), Poesia Reunida, pref. Maria João Reynaud, Lisboa, D. Quixote.

--- (2012), Poemas para Leonor, Lisboa, D. Quixote.

Kant et alii (1991), Qu'est.ce que les Lumières?, ed. Jean Mondot, Saint-Etienne, Ed. de l’Université.

Liborel, Hugues (1988), Les Fileuses, in « Dictionnaire des Mythes Littéraires », nouvelle édition augmentée, dir. Pierre Brunel, s. l., Editions du Rocher, pp. 612-634.

Malato, Maria Luísa (2014-2016), “'As Luzes' de Maria Teresa Horta: uma retórica da sensibilidade", Letras Convida. Revista de Literatura, Cultura e Arte, Número Temático: Maria Teresa Horta, 7, Lisboa, IN-CM/ CLEPUL, pp. 188-197.

Moyano, Y./ Coelho, S./ Mayos, G. eds. (2014), Postdisciplinariedad y desarrollo humano. Entre pensamiento y política, Barcelona, Red Ed.

Palmer, Richard E. (1986), Hermenêutica, trad. M. Luísa Ribeiro Ferreira, Lisboa, Edições 70. Veyne, Paul (1971). Comment écrit-on l'Histoire, Paris, Seuil. 
Maria Luísa Malato é professora associada com agregação na Faculdade de Letras da Universidade do Porto, onde é docente de História do Teatro Português, Estética e Retórica. Tem desenvolvido investigação na lírica e no teatro dos séculos XVIII-XIX, nomeadamente nos estudos sobre viagens imaginárias e utopia. Colaborou na História da Literatura Portuguesa da Editora Cátedra, de Madrid, e na Biblos, da Editora Verbo. Para além de artigos dispersos nestas matérias, é autora ou co-autora de vários livros, editados em Portugal, no Brasil e na Bélgica. 